\title{
Atividades extracurriculares, uma opinião
}

\section{Extracurricular activities, an opinion}

\author{
Maria Rita Margarido
}

$A_{\text {o ingressar no mundo universitário, uma }}$ das a nós, estudantes de medicina, são as atividades extracurriculares. Ligas acadêmicas, Atlética, Centro Acadêmico, grupos estudantis (de humanização hospitalar, religiosos), iniciação científica, monitorias são algumas dessas. Nesse contexto de inúmeras opções, unidas à inexperiência do recém-ingresso na universidade, torna-se um desafio fazer uma escolha consciente do que participar.

É sabido, por meio de alguns estudos. ${ }^{1,2}$ que alguns dos motivos mais relevantes para a procura de tais atividades incluem a busca pela prática médica, pelo aperfeiçoamente de técnicas e aquisição de conhecimento, por um melhoramento do currículo e um bônus em provas de residência. Ainda segundo estudos, principalmente sobre ligas acadêmicas ${ }^{3}$ as atividades excurriculares muitas vezes não servem a seus propósitos, consistindo em um meio que consome muito do já escasso tempo disponível aos estudantes do curso médico, além de muitas vezes não serem bem sucedidas em seus propósitos (por exemplo, promover a extensão) e reproduzirem vícios acadêmicos, por meio de cronogramas baseados em aulas teóricas. Vale lembrar que uma atividade extracurricular é, essencialmente, algo que o estudante escolhe realizar, e por isso deve ser algo que, teoricamente, este irá tratar com responsabilidade e desenvolverá um gosto por fazê-lo, muitas vezes mostrando muito mais dedicação a esta do que a atividades do "currículo formal".
Para se iniciar a discussão, uma breve síntese do conceito dos diversos tipos de currículos. Segundo Tavares et. al, ${ }^{1}$ o currículo é construído de forma a apresentar sua estrutura formal, que consiste na grade proposta pelo meio acadêmico de obrigações a serem cumpridas por todos os alunos. O currículo informal consiste na busca do aprendizado ainda dentro da instituição, mas não vinculado a planejamentos oficiais. O currículo paralelo, por sua vez, é aquele que consiste na busca de experiências fora dos muros do meio acadêmico (geralmente atividades ligadas à prática). Por fim, o currículo oculto situa o pano de fundo do processo de formação, perpassando todos os demais currículos (Figura 1). Dessa forma, as atividades extracurriculares seriam principalmente ferramentas de construção do currículo paralelo e informal, a fim de suprir eventuais falhas e necessidades não contempladas no currículo formal. Dentro do currículo paralelo, existem aquelas atividades classificadas como de Ensino (ex. Monitorias), Pesquisa (ex. Iniciação científica) e Extensão (ex. Ligas).

Inicio pela atividade talvez mais popular, as $\mathrm{Li}$ gas Acadêmicas, que visam principalmente o contato precoce do aluno com a prática médica e assuntos que sejam de seu interesse. Na vivência das Ligas, percebo que estas são muito mais procuradas por alunos do primeiro ao terceiro ano, e sua procura no internato inexpressiva, o que mais uma vez elucida seu papel de contato com a prática médica, praticamente inexistente nos dois primeiros anos do curso. Neste
Acadêmica do terceiro ano de Ciências Médicas da FMRP-USP, integrante do grupo PET-FMRP, aluna de Iniciação Científica da Divisão de Cirurgia Digestiva do Departamento de Cirurgia e Anatomia - FMRP-USP.
Artigo recebido em 12/03/2013 Aprovado para publicação em 20/03/2013 
sentido, as ligas proporcionam um ambiente favorável ao aprendizado e ao convívio entre estudantes, criando oportunidades de discussões e aquisição de conhecimento. As ligas, no entanto, deveriam se pautar no tripé universitário (ensino, pesquisa, extensão), principalmente em extensão. A vivência mostra, no entanto, que a grande maioria das ligas, na FMRP, falham em realizar projetos de pesquisa e mesmo de promover atividades de extensão. O que acontece muitas vezes é a reprodução de modelos de ensino do meio acadêmico, em sua grande maioria, com palestras e aulas teóricas. Além disso, a prática médica promovida pelas ligas muitas vezes ocorre sem supervisão, o que pode significar diversos problemas de ordem técnica e mesmo ética nas atividades de extensão. Por isso, como mostra Filho, ${ }^{3}$ as ligas são atividades que deveriam ser repensadas, para melhor suprir as necessidades de alunos. Apesar disso, são atividades muito ricas em conhecimento e proveitosas. ${ }^{4}$

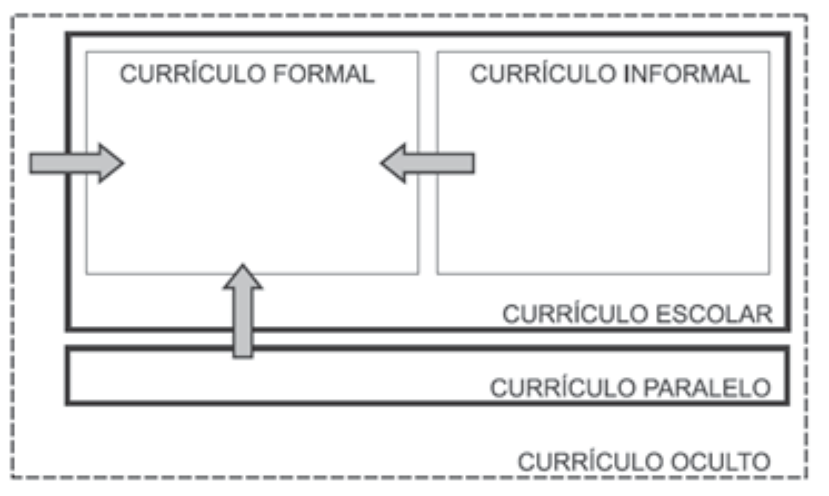

Figura 1. Currículo Formal, Informal, Escolar, Paralelo e Oculto. Movimentos do planejamento curricular. (Reproduzido de Tavares et al, 2007)

Nesse mesmo contexto de complementar a graduação, encontram-se opções como grupos estudantis. Refiro-me aqui ao grupo PET (Programa de Educação Tutorial), do qual participo. Trata-se de um grupo de alunos do curso médico, aliados a um tutor (no nosso caso, Prof. Dr. Antônio Pazin Filho), vinculados ao Ministério da Educação, que realizam atividades do tripé universitário a fim de suprir demandas, que achem coerentes, dos diversos alunos do curso médico e de seu próprio grupo. Para tal, são realizados eventos culturais, de ensino ou científicos (workshops, simpósios, sarais) e atividades internas, como discussão de temas quistos pelos integrantes ("projetinhos").
Estes últimos algumas vezes são expandidos e levados para fora do grupo, com a realização de apresentação de filmes e discussões posteriores com profissionais da área abordada (CinePET). São feitas também atividades para o desenvolvimento da língua estrangeira (reuniões em Inglês), desenvolvimento da leitura e discussão de livros, planejamento de atividades de extensão (Cursinho Popular do PET - Medicina, um cursinho para alunos carentes) e projetos de pesquisa (atualmente, sobre a percepção de alunos dos primeiros anos ,dos diversos cursos do Campus de Ribeirão Preto da USP, sobre o serviço de emergência). O PET é uma experiência, portanto, que se classificaria como holística, pois possui atividades que contemplam Ensino, Pesquisa e Extensão. Atualmente vem crescendo no campus de Ribeirão Preto, com a mais nova formação do grupo PET-Direito e os já existentes PET-Química e PET-Enfermagem, além do PET-Medicina. O grupo é um ótimo ambiente para se aprender como funciona a estrutura da universidade, aprender a conviver com pessoas diferentes, a lidar com problemas diversos, organizar eventos, debater idéias, construir um "currículo informal" por meio do convívio com o tutor, e mesmo fazer amizades.

Outra atividade popular é a iniciação científica, que proporciona ao aluno um convívio com práticas, técnicas e conhecimento científico. Orientado por um docente, o aluno escreve projetos, realiza atividades práticas e pode até mesmo apresentar trabalhos em congressos ou publicar artigos em periódicos científicos. É então uma atividade muito rica em termos de conhecimento, pois permite além de adquirir habilidades manuais, desenvolver o pensamento científico, estatístico, de escrita e mesmo de convívio com docentes.

Por fim, a participação no grupo FelizIdade, de humanização hospitalar (um grupo de alunos que visita às enfermarias da geriatria do HC para conversar com os pacientes, tocar músicas, fazer teatros) é muito útil em termos de desenvolvimento da comunicação além de ser muito gratificante pessoalmente, ao encontrar tamanha gratidão. É também um dos melhores grupos para se conquistar amizades, além de ser o único grupo em que não existe uma hierarquia e um grupo de pessoas em comando.

Podemos ver que, as atividades extracurriculares, apesar de apresentarem alguns problemas em sua concepção e muitas vezes serem dispendiosas em tempo, promovem ao aluno uma formação ampla e mais 
completa do que proporciona o currículo formal. Recomendo a participação para todos os alunos, atentando, porém ao cuidado de não haver sobrecarga nas atividades, pois elas, assim, deixariam de servir a seu propósito para ser algo desagradável e cansativo.

Uma boa escolha ajuda bastante, pois quando gostamos do que fazemos, fica muito mais fácil construir algo bem feito. Desta forma, a atividade extracurricular nos acrescenta muitas coisas que ainda ansiamos, mesmo com todas as atividades da graduação, valendo todo o tempo dedicado.

\section{Referências Bibliográficas}

1. Tavares CHF, Maia JA, Muniz MCH, Malta MV, Magalhães BRC, Thomaz ACP. O currículo paralelo dos estudantes da terceira série do curso médico da Universidade Federal de Alagoas. Rev Bras Educ Med. 2007; 31:245-53.

2. Tavares AP, Ferreira RA, França EB, Junior CAF, Lopes GC, Dantas NGT, Cardoso SAV. O " currículo paralelo " dos estudantes de medicina da Universidade Federal de Minas Gerais. Rev Bras Educ Med. 2007; 31:254-65.

3. Hamamoto Filho PT. Ligas acadêmicas: motivações e críticas a propósito de um repensar necessário. Rev Bras Educ Med. 2011; 35:535-43.

4. Santana ACDA. Ligas acadêmicas estudantis.O mérito e a realidade. Medicina (Ribeirão Preto) 2012; 45:96-8. 